merits of hospital and community care for the mentally ill. A Concerted Action Programme is a method of support adopted by CEC whereby the CEC undertakes to pay the costs of coordination and of bringing together researchers from various countries while the actual research is paid for and executed by each country.

The planning group concerned with the development of the study proposals included:

Dr Andre Baert, Brussels, Belgium

Professor J. Casselman, Leuven, Belgium

Professor C. L. Cazzullo, Milan, Italy

Dr Jose Sampaio Faria, Copenhagen, Denmark

Professor T. J. Fahy, Galway, Eire

Professor R. Giel, Groningen, Netherlands

Professor H. Hafner, Mannheim, Federal Republic of Germany

Dr J. H. Henderson, Northampton, UK

Professor I. Pelc, Brussels, Belgium

Professor M. Shepherd, London, UK.

The current programme of the CEC Medical and Health Research Committee is the fourth of a series and is being carried out during the years 1987 to 1991. CEC action on health services research in general and in the field of mental health in particular has gained support and favour only during this fourth programme. Major areas of concerted action projects at present include research on cancer prevention, infections in intensive care units and health status assessment in chronic and disabling medical conditions. Research is being conducted on systems of health care delivery, including perinatal care delivery, care delivery for the elderly, primary health care delivery and its interfaces and care delivery for the brain damaged following head injury. Research is supported also on health care organisation which includes activities on cost containment in health care, on health information systems, on the use of DRG to support hospital management and on economic aspects of AIDS.

Health technology assessment is another area of health services research which includes at present the analysis of regional variations in the use of health technologies, quality assurance in health care, legal aspects of medical devices and cost effectiveness of antenatal screening by ultrasound.

The advent of a mental health study in the CEC fourth programme of Medical and Health Research is to be welcomed and will provide an important contribution of knowledge and fact to policy makers, administrators and clinicians on a topical policy movement for which relatively few evaluative studies exist at present.

St Andrew's Hospital

JOHN H. HENDERSON

\section{Court requests for psychiatric medical reports}

Dear Sirs

Psychiatric medical reports are often requested by the courts either as part of the evidence for the trial of the alleged offender, or between conviction and sentencing. Often these requests reach the psychiatrist via the Probation Service and many of these requests are to see the alleged offender as an out-patient. Sometimes an assessment in prison is requested. Four out of five individuals for an outpatient assessment failed to attend and the fifth individual initially attended, but failed to attend for follow-up appointments after the court case was over. This non-attendance figure is considerably higher than reports of $20-57 \%$ psychiatric out-patients failing to keep their appointments (Baekland \& Lundwall, 1975; Shah \& Lynch, 1989).

As the courts are requesting a medical report it would be in the interest of the alleged offender to attend. Several factors have been reported with the associated non-attendance (Baekland \& Lundwall, 1975; Frankel et al, 1989): younger age, difficulty of getting time off work, short notice of appointment, and insufficient information about appointment (Frankel et al, 1989). All these factors could apply to the above patients.

The contents of the report may have an important bearing on the individual's case and one wonders whether there should be an obligation on the part of the courts, or the Probation Service, to ensure that the psychiatrist has access to the individual. It would also ensure a more effective and efficient use of the psychiatric out-patient clinics in the Health Service. Sometimes this is achieved by the psychiatrist visiting the patient in prison. However, the problem arises where the alleged offence is not serious enough to require prison and perhaps a mechanism should be instituted whereby the psychiatrist has ready access to see individuals.

\section{Whittington Hospital}

London N19 5NF

AJit ShaH

\section{References}

BAEKLAND, F. \& LUNDWALL, L. (1975) Dropping out of treatment. A critical review. Psychological Bulletin, 82, 738-783.

Frankel, S., Farrow, A. \& West, R. (1989) Nonattendance or non-invitation? A case-control study of failed out-patient appointments. British Medical Journal, 298, 1343-1345.

SHAH, A. K. \& LYNCH, S. (1989) Characteristics of patients in a psychiatric follow up clinic. Paper presented at the Spring meeting of the Royal College of Psychiatrists 1989. 